\title{
Phylogeny of Neoparamoeba strains isolated from marine fish and invertebrates as inferred from SSU rDNA sequences
}

\author{
Iva Dyková ${ }^{1,2}$, Barbara Nowak ${ }^{3}$, Hana Pecková ${ }^{1}$, Ivan Fiala ${ }^{1,2}$, Philip Crosbie ${ }^{3}$, \\ Helena Dvořáková ${ }^{1}$ \\ ${ }^{1}$ Biology Centre of the Academy of Sciences of the Czech Republic, Institute of Parasitology, and ${ }^{2}$ Faculty of Biological \\ Sciences, University of South Bohemia, Branišovská 31, 37005 České Budějovice, Czech Republic \\ ${ }^{3}$ School of Aquaculture, Aquafin CRC, Tasmanian Aquaculture and Fisheries Institute, University of Tasmania, Launceston, \\ Tasmania 7250, Australia
}

\begin{abstract}
We characterised 9 strains selected from primary isolates referable to Paramoeba/Neoparamoeba spp. Based on ultrastructural study, 5 strains isolated from fish (amoebic gill disease [AGD]-affected Atlantic salmon and dead southern bluefin tuna), 1 strain from netting of a floating sea cage and 3 strains isolated from invertebrates (sea urchins and crab) were assigned to the genus Neoparamoeba Page, 1987. Phylogenetic analyses based on SSU rDNA sequences revealed affiliations of newly introduced and previously analysed Neoparamoeba strains. Three strains from the invertebrates and 2 out of 3 strains from gills of southern bluefin tunas were members of the $N$. branchiphila clade, while the remaining, fish-isolated strains, as well as the fish cage strain, clustered within the clade of $N$. pemaquidensis. These findings and previous reports point to the possibility that $N$. pemaquidensis and $N$. branchiphila can affect both fish and invertebrates. A new potential fish host, southern bluefin tuna, was included in the list of farmed fish endangered by $N$. branchiphila. The sequence of $P$. eilhardi (Culture Collection of Algae and Protozoa [CCAP] strain 1560/2) appeared in all analyses among sequences of strain representatives of Neoparamoeba species, in a position well supported by bootstrap value, Bremer index and Bayesian posterior probability. Our research shows that isolation of additional strains from invertebrates and further analyses of relations between molecular data and morphological characters of the genera Paramoeba and Neoparamoeba are required. This complexity needs to be considered when attempting to define molecular markers for identification of Paramoeba/Neoparamoeba species in tissues of fish and invertebrates.
\end{abstract}

KEY WORDS: Neoparamoeba strains $\cdot$ Paramoeba eilhardi $\cdot$ Phylogeny $\cdot$ Invertebrate infections

Resale or republication not permitted without written consent of the publisher

\section{INTRODUCTION}

Over the past 20 yr, new data on amoebic gill disease (AGD) in farmed marine fish have become available at an increasing rate. Three important steps have been made to date in investigations on the aetiology of this disease: (1) The causative agent of gill infections of coho salmon Oncorhynchus kisutch (Walbaum, 1792) reared in seawater was diagnosed as Paramoeba pemaquidensis Page, 1970 by Kent et al. (1988) and the same agent of AGD was reported in turbot Scophthalmus maximus (L.) and Atlantic salmon Salmo salar (L.) (Roubal et al.1989, Munday et al. 1990, Dyková et al. 1998). (2) Amoeba strains isolated from gills of different fish hosts and referred to originally as Paramoeba species have been assigned to Neoparamoeba Page, 1987 (Dyková et al. 2000); attention has focused on ultrastructural features used by Page (1987) to discriminate Neoparamoeba from Paramoeba; the value of morphometric data for species diagnosis within the 
genus Neoparamoeba is considered questionable (Dyková et al. 2000, 2005b). (3) Due to size differences and a great diversity of shape within clonal cell populations of Neoparamoeba strains, comparison of strains has concentrated on their molecular characteristics. Taxonomic relatedness of Neoparamoeba strains has been inferred from phylogenetic analyses of SSU rDNA sequences, and branching pattern has been explored for the establishment of a new Neoparamoeba species (Fiala \& Dyková 2003, Dyková et al. 2005b)

When first conclusions on the aetiology of AGD were reported by Kent et al. (1988), species of the genus Paramoeba Schaudinn, 1896 were already known as causative agents of invertebrate mortalities. More than $70 \mathrm{yr}$ after the description of the type species of the genus Paramoeba Schaudinn, 1896 ( $P$. eilhardi Schaudinn 1896), which was isolated from the water of a marine aquarium (information taken from Chatton 1953), another species, P. perniciosa Sprague, Beckett \& Sawyer, 1969 was identified. It repeatedly caused mortalities of blue crabs Callinectes sapidus along the coast of North Carolina (USA), and was also identified as a parasite of the crustaceans Cancer irroratus and Homarus americanus (Sawyer 1976, Johnson 1977). $P$. invadens Jones, 1985, recovered from the green sea urchin Strongylocentrotus droebachiensis, inflicted massive kills along the Atlantic coast of Nova Scotia, Canada through the years 1980 to 1983 (Jones 1985).

Paramoeba and Neoparamoeba species, together with Janickina pigmentifera (Grassi, 1881) and J. chaetognathi (Grassi, 1881) (Chatton 1953), which were described as parasites of Spadella spp. (Chaetognatha), form a group of amoebae of extraordinary importance, because of their potential pathogenicity for marine fish and invertebrates. Page included them in the category of parasitic marine gymnamoebae (Page 1983).

The pathogenicity of Paramoeba and Neoparamoeba spp., the epizootic nature of infections and impacts of mass mortalities on the fishing economy and environment are strong reasons for research commitment. Moreover, 6 species of Paramoeba, Neoparamoeba and Janickina have in common another important phenomenon: they live in permanent association with eukaryotic symbionts located in their cytoplasms (Grell \& Benwitz 1970, Page 1970, Perkins \& Castagna 1971, Hollande 1980, Dyková et al. 2000, 2003). This in itself provides a strong motivation for a meticulous comparison of strain representatives of this group of naked amoebae and also of their eukaryotic endosymbionts.

Because a large number of strains have been isolated from AGD, considerably more information is available on agents of this disease than on agents of amoebic infections of invertebrates. Unfortunately, the epizootic agents found in crustaceans and echinoids (Sprague et al. 1969, Johnson 1977, Jones 1985) were not preserved in culture collections, and agents of more recent mortalities of American lobsters were not isolated (Mullen et al. 2004, 2005). The first and only SSU rDNA sequence of a strain representative of the genus Paramoeba ( $P$. eilhardi, Culture Collection of Algae and Protozoa [CCAP] strain 1560/2) was deposited in GenBank in 2004. A sudden surge of interest in researching the amoebic diseases of invertebrates which was triggered by outbreaks of disease in American lobsters (Mullen et al. 2004, 2005) brought new insights into the etiology of amoebic diseases in invertebrates, and at the same time, opened a broad field for complementary investigations.

The present study started as an attempt to isolate Paramoeba strains from invertebrates and obtain information about their relationships with Neoparamoeba strains characterised previously. Data we have acquired on new strains from invertebrates and fish, supplemented by those retrieved from the GenBank database, are used to present phylogenetic relationships inferred from SSU rDNA sequences.

\section{MATERIALS AND METHODS}

Nine newly isolated strains were included in the study; 5 of them were isolated from fish, 1 from netting of floating sea cages in Atlantic salmon farms, and 3 from invertebrates. The designations and origins of strains are specified in Table 1. All successful isolations from southern bluefin tuna were from dead fish recovered by divers. The isolation success rate was $33.3 \%$ (isolates from 3 of 9 dead specimens sampled between summer 2004 and winter 2005). No amoebae were isolated from gills of harvested tuna (4 attempts).

The handling of primary isolates, culturing and harvesting for ultrastructural and molecular studies followed procedures described for fish-isolated strains by Dyková et al. (2000) and routinely used in our previous study (Dyková et al. 2005b). All strains were subcultured weekly using non-seeded malt and yeast extract in $75 \%$ seawater agar (MY75S, UK National Culture Collection [UKNCC] 2001 catalogue).

For morphological and molecular studies, purified cell populations were used, either derived from one cell, or, when classical clonal procedures failed, from several cells of presumably common origin (growing as a separate group of closely adjacent cells on the agar surface). Light and electron microscopical methods used on newly isolated strains were those of Dyková et al. (2005b).

DNA extraction, amplification and sequencing were performed according to the protocol of Fiala \& Dyková (2003), also used in our latest report on Neoparamoeba species (Dyková et al. 2005b). The set of SSU rDNA se- 
Table 1. Amoeba strains included in the present study

\begin{tabular}{|ll|}
\hline Host species & Origin \\
Amoeba strain/clone & \\
\hline Thunnus maccoyii, dead (gills) & \\
TUN1/I & Port Lincoln, Australia \\
TG1162 & Port Lincoln, Australia \\
TG1267 & Port Lincoln, Australia \\
Salmo salar (gills) & \\
GILLRICH3/I & Tasmania, Australia \\
WT2708/I & Tasmania, Australia \\
Salmo salar (net material of sea cages) & \\
NET12AFL/I & Tasmania, Australia \\
Paracentrotus lividus & \\
AMOPI & Cretan Sea, Kárpathos Island, \\
Heliocidaris erythrogramma & Greece \\
SU4 & Tamar River, Georgetown, \\
Callinectes sapidus & Tasmania, Australia \\
RP & \\
\end{tabular}

(Ts/Tv) ratios were 1:1, 1:2 and 1:3. In addition to clade support assessed with bootstrapping of 1000 replicates, Bremer decay indices were established. For the ML analysis, the likelihood ratio test (LRT) implemented in Modeltest v. 3.06 (Posada \& Crandall 1998) was used to determine the best model of evolution. Based on the LRT, the ML was performed with the GTR $+\mathrm{I}+\Gamma$ model of evolution. The estimated $\alpha$-parameter was 0.4523 , the number of substitution types was 6 and the proportion of invariable sites was 0.2934 . The best tree was determined using Tree Bisection-Reconnection (TBR) rearrangements. The bootstrap analysis (500 replicates) was done using the Seqboot in PHYLIP, v. 3.6a3 (Felsenstein 2002) and the PHYML program (Guindon \& Gascuel 2003).

Newly introduced strains, as well as those from our previous study, are cryquences aligned the present study included the whole data set in Dyková et al. (2005b), supplemented with 9 sequences obtained from our study, and another 4 retrieved from the GenBank database. The latter included the first sequence for the reference strain of Paramoeba eilhardi (CCAP 1560/2), the duplicated sequence of $N$. aestuarina strain CCAP 1560/7, and 2 sequences from amoebae isolated from lobsters from Long Island Sound, USA, along with those of Korotnevella and Vexillifera as representatives of paramoebid and vexilliferid (PV) lineages of Gymnamoebae (Peglar et al. 2003), respectively. Vannella anglica and V. aberdonica represented an outgroup. In total, 52 sequences were aligned in the Clustal_X program (Thompson et al. 1997) with a gap opening/gap extension penalty of $8 / 2$. Corrections were done by eye using the BioEdit sequence alignment editor (Hall 1999). The alignment is available from the authors upon request. Phylogenetic analyses were performed using the maximum parsimony (MP) and maximum likelihood (ML) methods. In addition, Bayesian inference of phylogeny (BI) was applied. MP and ML procedures were carried out with the PAUP* package, version $4.0 \mathrm{~b} 10$ (Swofford 2001). For BI procedures, the MrBayes program v. 3.0 (Ronquist \& Huelsenbeck 2003) was used. Models of nucleotide substitution were evaluated using MrModeltest v. 2.2 (Nylander et al. 2004). The model GTR $+\mathrm{I}+\Gamma$ was chosen. Posterior probabilities were computed using the Markov Chain Monte Carlo method with 500000 generations. The length of burn-in period was 100000 generations. MP analysis was done using a heuristic search with random addition of taxa (10 replications) and the ACCTRAN-option. Gaps were treated as missing data. Transition/transversion opreserved and stored in liquid nitrogen in the culture collection of the Institute of Parasitology (Biology Centre of the Academy of Sciences of the Czech Republic).

\section{RESULTS}

\section{Morphology and fine structure of trophozoites}

Light microscopical observation of 16 primary isolates growing on the surface of agar qualified suitable groups of cells for subculturing and detailed study. As a result of subculturing, with attention focused on step-by-step purification of cell populations, 9 strains (listed in Table 1) having characteristics of the order Dactylopodida (Smirnov et al. 2005) and family Paramoebidae (Poche, 1913) Page, 1987 were selected (Fig. 1). Each strain in Fig. 1 is represented by the most typical trophozoites seen in hanging drop preparations using Nomarski DIC (differential interference contrast) light microscopy. They were selected from a series of images taken during the long-term culturing. Trophozoites of individual strains differed in size only; their morphotypes were identical. All of them contained endosymbionts, occasionally with more than 2 per host cell. Using descriptions given by Page (1987) and previous ultrastructural studies (Dyková et al. 2000, 2005b), our transmission electron microscopic analyses assigned all strains listed in Table 1 to the genus Neoparamoeba Page, 1987. Basic ultrastructural characteristics common to these strains are shown in Figs. 2 to 8 (all specimens isolated from invertebrates). 


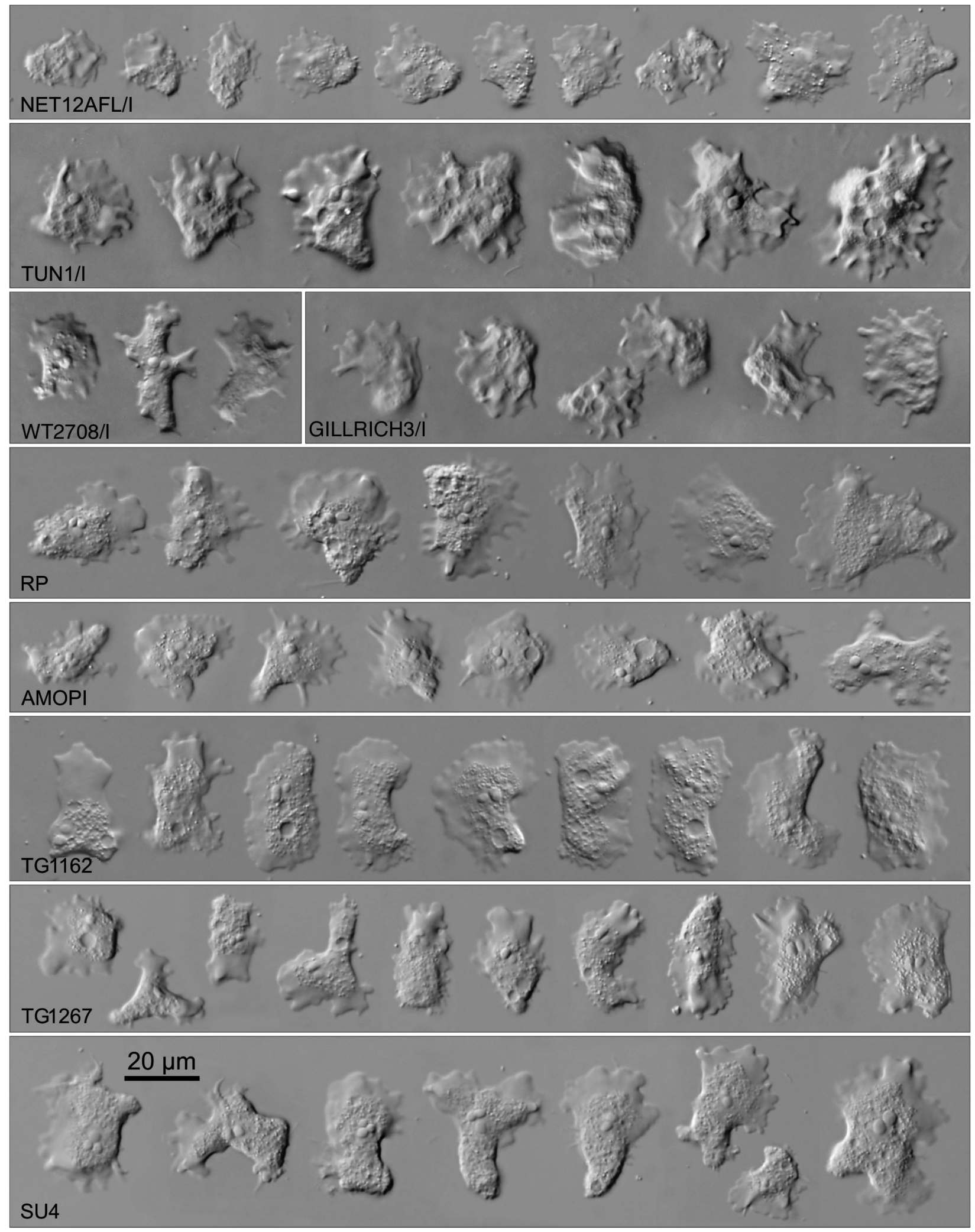

Fig. 1. Trophozoites representative of newly characterised Neoparamoeba strains. Images are marked with codes of strains (see Table 1); codes are used in phylogenetic trees. Scale bar applies to all strains shown. Nomarksi differential interference contrast 


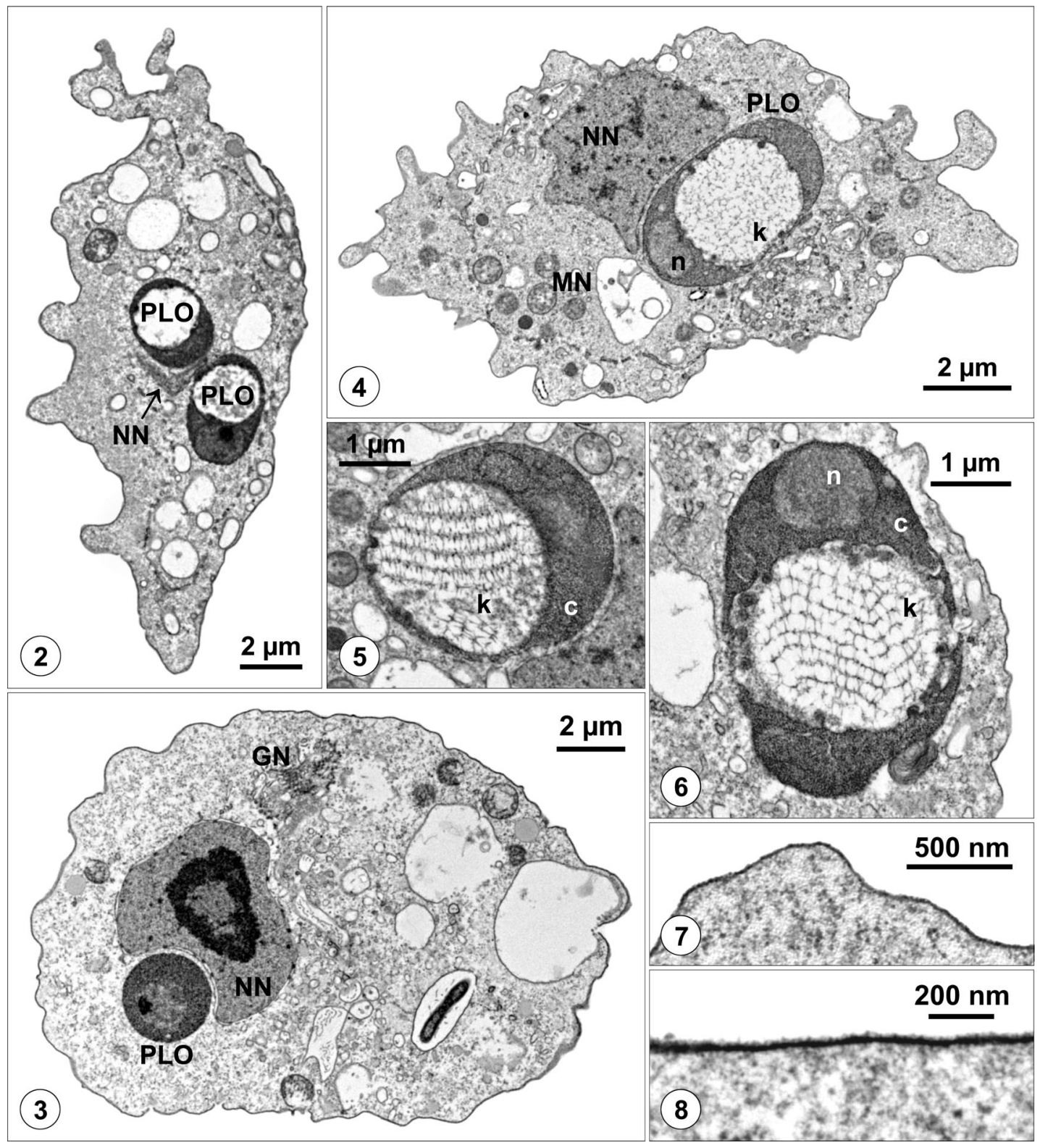

Figs. 2 to 8. Trophozoites representative of Neoparamoeba strains isolated from invertebrate hosts and details of their ultrastructure; transmission electron microscopy; GN = Golgi apparatus, $\mathrm{MN}=$ mitochondria, $\mathrm{NN}=$ Neoparamoeba nucleus, $\mathrm{PLO}=$ Perkinsiella amoebae-like endosymbiont, $\mathrm{c}=$ cytoplasm of PLO, $\mathrm{k}=$ kinetoplast of PLO, $\mathrm{n}=$ nucleus of PLO. Fig. 2 \& Fig. 3. Trophozoites of RP strain isolated from Callinectes sapidus; PLO sections in Figs. 2 \& 3 were cut at different levels. Fig. 4. Trophozoite of AMOPI strain isolated from Paracentrotus lividus; PLO with bipolar symmetry is located alongside host nucleus. Fig. 5 \& Fig. 6 . PLOs with typical arrangement of kDNA network. Fig. 7. Trophozoite cell surface of RP strain. Fig. 8. Amorphous glycocalyx of SU4 strain trophozoite isolated from Centrostephanus rodgersii

\section{Molecular phylogeny and taxonomy based on SSU rDNA sequences}

Phylogenetic relationships of strains inferred from sequence-based analyses are presented in the MP tree supplemented with nodal support values and Bremer decay indices (Fig. 9). The branching pattern of the tree clearly defines 3 clades, those that are known from previous analyses of sequences from fish-isolated and environmental Neoparamoeba strains (Dyková et al. 2005b). Three strains that we isolated from invertebrates ( 2 from sea urchins and 1 from crab) collected in localities far from one another (Greece, Tasmania, Australia and the Gulf Coast, USA, respectively) clus- 


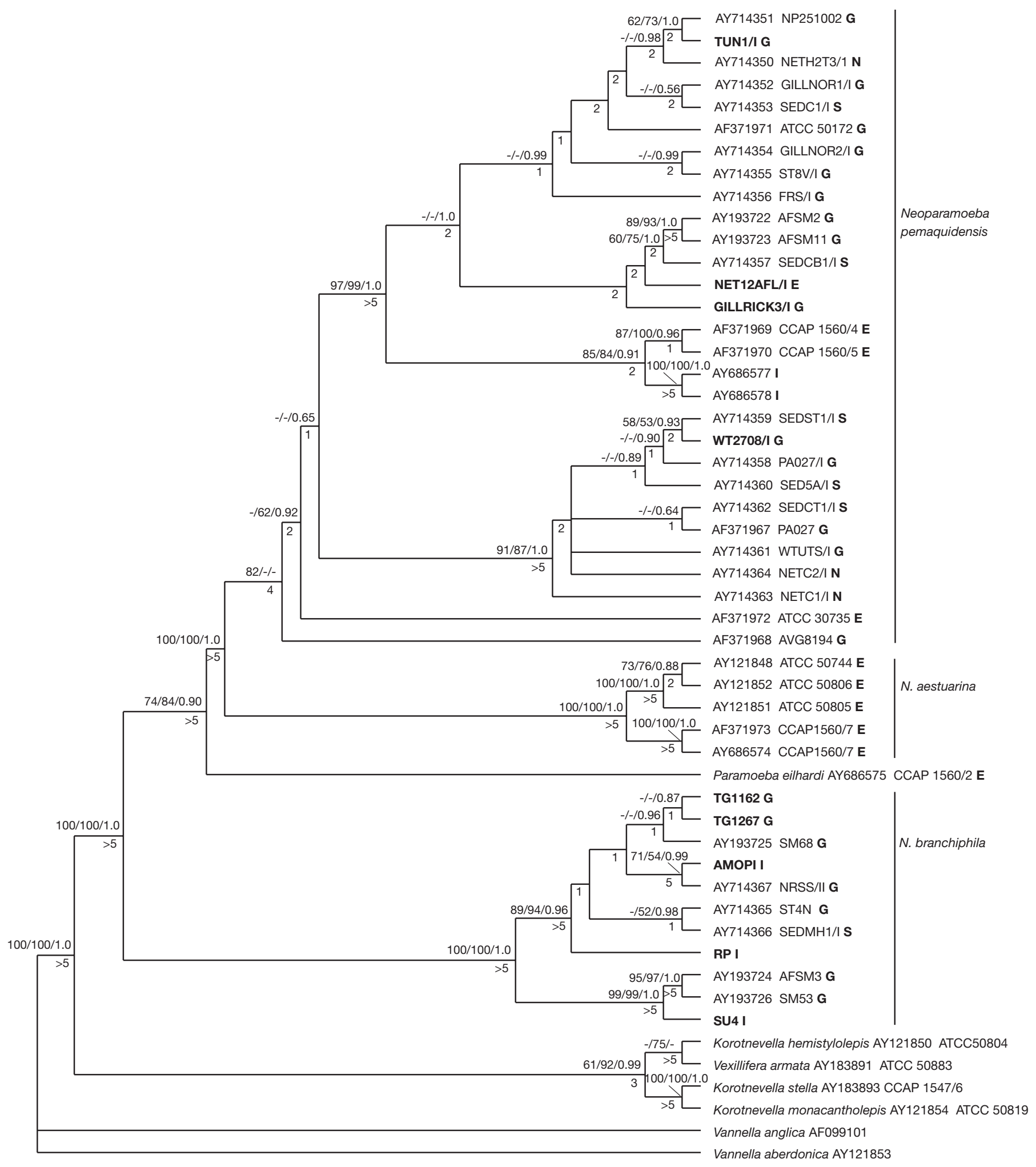

Fig. 9. Maximum parsimony (MP) tree of the SSU rDNA sequences; strict consensus of 2 most parsimonious trees (transition/transversion $[\mathrm{Ts}: \mathrm{Tv}]=1: 2,3288$ steps, consistency index $[\mathrm{CI}]=0.79$, retention index $[\mathrm{RI}]=0.64$ ). Values above the lines indicate nodal support (MP with Ts:Tv = 1:2/maximum likelihood [ML]/Bayesian inference [BI]); Bremer decay indices are given below the lines. Data retrieved from the GenBank database are presented as accession numbers of sequences, followed by codes of strains, while the origin of each newly acquired sequence is given as bold-faced code of strain. Abbreviations used for origin of strains are as follows: $\mathrm{G}$ = gills, $\mathrm{S}=$ sediments, $\mathrm{N}$ = net material, $\mathrm{E}=$ environmental origin and $\mathrm{I}=$ invertebrates 
ter together with 2 of 3 strains isolated from gills of southern bluefin tunas (Australia) within the clade of $N$. branchiphila. The clade of $N$. pemaquidensis is enlarged by the inclusion of 4 strains we have introduced, i.e. 1 strain isolated from gills of southern bluefin tuna, 2 from gills of Atlantic salmon, and 1 from netting of a floating Atlantic salmon farm cage. The clade of $N$. aestuarina is enlarged by the inclusion of the new sequence for the CCAP 1560/7 strain.

Our work does not change the existing concept of potential candidates for agents of AGD. We identified specimens belonging to Neoparamoeba pemaquidensis and $N$. branchiphila among 5 new strains isolated from fish. Mullen et al. (2005) identified sequences generated from lobster amoebae which corresponded to $N$. pemaquidensis (closely related to sequences of reference strains CCAP 1560/4 and CCAP 1560/5), and in our study $N$. branchiphila was identified as a possible agent of infections in invertebrates.

The position of the strain representative of Paramoeba eilhardi (CCAP 1560/2) among the clades of Neoparamoeba was surprising, but it was stable in all analyses performed and well supported by the bootstrap value, Bremer index and Bayesian posterior probability. The only tree position that differed depending on the method of phylogenetic analysis was that of strain AVG8194 (AF371968). Contrary to results of all MP analyses (Ts/Tv 1:1, 1:2 and 1:3) and ML and BI computed with models in which gamma distribution is not used to account for rate variation among sites (JC69, F81 or HKY), in ML and BI (both GTR+I+Г), AVG8194 joined Neoparamoeba aestuarina strains.

\section{DISCUSSION}

Our study, stimulated by a general interest in the pathogenicity of free-living amoebae in aquatic organisms, by progress made toward an understanding of fish infections, and by the lack of information on agents of amoebic infections of invertebrates, brought new and unexpected information. Our expectation that the set of SSU rDNA sequences of Neoparamoeba strains could be extended to include those belonging to morphologically different strains of the genus Paramoeba failed. The aim of including the sequence of the Paramoeba strain into an extended sequence set for Neoparamoeba was restricted to the environmental strain of $P$. eilhardi CCAP 1560/2, also used as unique Paramoeba strain in the study of Mullen et al. (2005). However, our analysis of the extended set of Neoparamoeba sequences resulting in assignment of our strains from invertebrates into $N$. branchiphila, introduces a second species of the genus that is pathogenic in invertebrates, along with N. pemaquidensis (Mullen et al. 2005). Unfortunately, $N$. pemaquidensis, the agent of amoebic disease of American lobster (Mullen et al. 2004, 2005) was not isolated and stored for future studies. Its identification was not simple, as it is based on phylogenetic analyses of sequences of genomic DNA extracted from host tissue samples.

To the best of our knowledge, the number of amoeba strains of interest isolated from invertebrates during the present study is unique. The lack of strains isolated from invertebrates that are stored in culture collections is surprising considering the fact that Paramobea invadens, for example, was isolated from radial nerves and water vessels of the green sea urchin Strongylocentrotus droebachiensis, then readily cultured on agar plates and used for experimental infections (Jellet et al. 1988). It is possible that some tissue-invading amoebae are more difficult to maintain in agar plate cultures or liquid media than those isolated directly from water. The individual fishes and invertebrates we have attempted to isolate were randomly selected from asymptomatic specimens. Based on our experience with AGD, we consider this sampling procedure reasonable. Jellet et al. (1988) also proved experimentally that trophozoites of $P$. invadens are present in the radial nerves of echinoids well before the onset of visible symptoms of the disease. This shows that even sampling that is not related to outbreaks of amoebic diseases can help us accumulate new data in the field. However, it is possible that free-living Neoparamoeba strains colonised southern bluefin tuna after death, as we were not able to culture amoebae from harvested (healthy) fish, and no AGD-like lesions have been seen so far in this fish species (B. Nowak unpubl.). Neoparamoeba strains can colonise gills of previously uninfected dead Atlantic salmon (Douglas-Helders 2000), so it is possible that the gills of southern bluefin tuna were colonised after death. Further evidence is needed to confirm whether Neoparamoeba spp. are potential pathogens of southern bluefin tuna.

The data set enlarged with sequences of Neoparamoeba branchiphila pointed out a strange position of the SSU rDNA sequence of Paramoeba eilhardi, i.e. its incorporation into sequences of Neoparamoeba strains. The controversial phylogenetic position of $P$. eilhardi can be interpreted in various ways. If more sequences of strains assigned morphologically to $P$. eilhardi were available, and if they clustered together in the same tree position, this would likely be convincing evidence that phylogenetic relationships inferred from SSU rRNA gene sequences do not reflect ultrastructural features discriminating Paramoeba from Neoparamoeba. This is the case for Vannella and Platyamoeba species (Dyková et al. 2005a). With only one sequence of a strain representative of Paramoeba available, analysis of the organism sequenced should 
be done. The CCAP (now known as the UKNCC) acquired this strain in 1960 from a reputable investigator, K. G. Grell, who published several papers on P. eilhardi (Grell 1961, Grell \& Benwitz 1966, 1970) and documented the ultrastructural details (boat-shaped scales observed on the cell surface) rather well. However, we know of no reports on the deposition of clonal cultures in protist collections, or of recent ultrastructural verification of species determination made before the sequence was prepared in 2004. Our previous attempt to characterise this strain more than $40 \mathrm{yr}$ after K. G. Grell deposited it in the CCAP failed due to an extreme overload of the culture with bacteria. Working previously with several 'strains' obtained from the UKNCC, we found that some of them were actually mixed cultures of 2 to 3 different species. This is an expected consequence of cryopreservation and deposition of non-clonal cultures, and sometimes may result from long-term storage of isolates subcultured for only a short period of time. Since the sequence for $P$. eilhardi is the only one available for the genus Paramoeba, there is an urgent need for more information about the reference strain, as well as comparisons with sequences from strains corresponding to $P$. invadens and $P$. perniciosa. It is possible that the strains described as representatives of the latter species were assigned to the genus Paramoeba primarily on the basis of the presence of Perkinsiella amoebaelike organisms (PLOs) in their cytoplasm.

Acknowledgements. The National Science Foundation of the Czech Republic (Project No. 206/05/2384), the Ministry of Education, Youth and Sports (MSM 6007665801) and a research project of the Institute of Parasitology, Academy of Sciences of the Czech Republic (Z60220518 and LC522) funded this study. Parts of this project were proudly sponsored by the International Science Linkages Program established under the Australian Government's innovation statement, 'Backing Australia's Ability'. Some of this work formed part of a project of Aquafin $\mathrm{CRC}$, and received funds from the Australian Government's CRCs Program, the Fisheries R\&D Corporation and other CRC Participants. We thank R. Morrison for isolating strain GILLRICH3 and B. Vincent for technical support.

\section{LITERATURE CITED}

Chatton E (1953) Classe des Lobosa Leidy, 1879. Ordre des Amoebiens nus ou Amoebaea. In: Grassé PP (ed) Traité de Zoologie Tom I, Fasc.II. Masson \& Cie., Paris, p 42-46

Douglas-Helders M, Nowak B, Zilberg D, Carson J, (2000) Survival of Paramoeba pemaquidensis on dead salmon: implications for management of cage hygiene. Bull Eur Assoc Fish Pathol 20:167-169

Dyková I, Figueras A, Novoa B, Fernandez-Casal J (1998) Paramoeba sp., an agent of amoebic gill disease of turbot Scophthalmus maximus. Dis Aquat Org 33:137-141

Dyková I, Figueras A, Perič Z (2000) Neoparamoeba Page, 1987: light and electron microscopic observations on six strains of different origin. Dis Aquat Org 43:217-223

Dyková I, Fiala I, Lom J, Lukeš J (2003) Perkinsiella amoebaelike endosymbionts of Neoparamoeba spp., relatives of the kinetoplastid Ichthyobodo. Eur J Protistol 39:37-52

Dyková I, Boháčová L, Fiala I, Macháčková B, Pecková H, Dvořáková H (2005a) Amoebae of the genera Vannella Bovee, 1965 and Platyamoeba Page, 1969 isolated from fish and their phylogeny inferred from SSU rRNA gene and ITS sequences. Eur J Protistol 41:219-230

Dyková I, Nowak BF, Crosbie PBB, Fiala I, Pecková H, Adams MB, Macháčková B, Dvořáková H (2005b) Neoparamoeba branchiphila n. sp., and related species of the genus Neoparamoeba Page, 1987: morphological and molecular characterization of selected strains. J Fish Dis 28: 49-64

Felsenstein J (2002) (Phylogeny Inference Package) version 3.6a3. Distributed by author. University of Genome Sciences, Seattle, WA

Fiala I, Dyková I (2003) Molecular characterization of Neoparamoeba strains isolated from gills of Scophthalmus maximus. Dis Aquat Org 53:11-16

Grell KG (1961) Über den 'Nebenkörper' von Paramoeba eilhardi Schaudinn. Arch Protistenkd 105:303-312

Grell KG, Benwitz G (1966) Die Zellhülle von Paramoeba eilhardi Schaudinn. Z Naturforsch 21b:600-601

Grell KG, Benwitz G (1970) Ultrastruktur mariner Amöben I. Paramoeba eilhardi Schaudinn. Arch Protistenkd 112: $119-137$

Guindon S, Gascuel O (2003) A simple, fast and accurate algorithm to estimate large phylogenies and maximum likelihood. Syst Biol 52:696-704

Hall TA (1999) BioEdit: a user-friendly biological sequence alignment editor and analysis program for Windows 95/ 98NT. Nucleic Acids Symp Ser 41:95-98

Hollande A (1980) Identification du parasome (Nebenkern) de Janickina pigmentifera à un symbionte (Perkinsella amoebae nov gen-nov sp) apparenté aux flagellés Kinetoplastidiés. Protistologica 16:613-625

Jellet JF, Wardlaw AC, Scheibling RE (1988) Experimental infection of the echinoid Strongylocentrotus droebachiensis with Paramoeba invadens: quantitative changes in the coelomic fluid. Dis Aquat Org 4:149-157

Johnson PT (1977) Paramoebiasis in the blue crab, Callinectes sapidus. J Invertebr Pathol 29:308-320

Jones GM (1985) Paramoeba invadens n. sp. (Amoebidae, Paramoebidae) a pathogenic amoeba from the sea urchin, Strongylocentrotus droebachiensis, in Eastern Canada. J Protozool 32:346-369

Kent ML, Sawyer TK, Hedrick RP (1988) Paramoeba pemaquidensis (Sarcomastigophora: Paramoebidae) infestation of the gills of coho salmon Oncorhynchus kisutch reared in sea water. Dis Aquat Org 5:163-169

Mullen TE, Russel S, Tucker MT, Maratea JL and 5 others (2004) Paramoebiasis associated with mass mortality of American lobster Homarus americanus in Long Island Sound, USA. J Aquat Anim Health 16:29-38

Mullen TE, Nevis KR, O'Kelly CJ, Gast RJ, Frasca S Jr (2005) Nuclear small-subunit ribosomal RNA gene-based characterization, molecular phylogeny and PCR detection of the Neoparamoeba from Western Long Island Sound lobster. J Shellfish Res 24:719-731

Munday BL, Foster CK, Roubal FR, Lester RJG (1990) Paramoebic gill infection and associated pathology of Atlantic salmon, Salmo salar, and rainbow trout, Salmo gairdneri, in Tasmania. In: Perkins FO, Cheng TC (eds) Pathology in marine science. Academic Press, New York, NY, p 215-222 
Nylander JAA, Ronquist F, Huelsenbeck JP, Nieves-Aldrey JL (2004) Bayesian phylogenetic analysis of combined data. Syst Biol 53:47-67

Page FC (1970) Two new species of Paramoeba from Maine. J Protozool 17:421-427

Page FC (1983) Marine Gymnamoebae. Institute of Terrestrial Ecology, Cambridge

Page FC (1987) The classification of 'naked' amoebae of phylum Rhizopoda. Arch Protistenkd 133:199-217

Peglar MT, Amaral Zettler LA, Anderson OR, Nerad TA and 6 others (2003) Two new small-subunit ribosomal RNA gene lineages within the subclass Gymnamoebia. J Eukaryot Microbiol 59:224-232

Perkins FO, Castagna M (1971) Ultrastructure of the Nebenkörper or 'secondary nucleus' of the parasitic amoeba Paramoeba perniciosa (Amoebida, Paramoebidae). J Invertebr Pathol 17:186-193

Posada D, Crandall KA (1998) Modeltest: testing the model of DNA substitution. Bioinformatics 14:817-818

Ronquist F, Huelsenbeck JP (2003) MrBayes 3: Bayesian phylogenetic inference under mixed models. Bioinformatics 19:

Editorial responsibility: Dieter Steinhagen,

Hannover, Germany
$1572-1574$

Roubal FR, Lester RJG, Foster CK (1989) Studies on cultured and gill attached Paramoeba sp. (Gymnamoebae: Paramoebidae) and the cytopathology of paramoebic gill disease in Atlantic salmon, Salmo salar L., from Tasmania. J Fish Dis 12:481-493

Sawyer TK (1976) Two new crustacean hosts for the parasitic amoeba, Paramoeba perniciosa. Trans Am Microsc Soc 94: 395-400

Smirnov A, Nassonova E, Berney C, Fahrni J, Bolivar I, Pawlowski J (2005) Molecular phylogeny and classification of the lobose amoebae. Protist 156:129-142

Sprague V, Beckett RL, Sawyer TK (1969) A new species of Paramoeba (Amoebida, Paramoebidae) parasitic in the crab (Callinectes sapidus). J Invertebr Pathol 14:167-174

Swofford DL (2001) PAUP*: phylogenetic analysis using parsimony, version 4.0b10. Sinauer Associates, Sunderland, MA

Thompson JD, Gibson TJ, Plewniak F, Jeanmougin F, Higgins DG (1997) The CLUSTAL_X windows interface: flexible strategies for multiple sequence alignment aided by quality analysis tools. Nucleic Acids Res 25:4876-4882

Submitted: March 9, 2006; Accepted: November 16, 2006 Proofs received from author(s): January 31, 2007 